Published in final edited form as:

$J$ Am Chem Soc. 2016 February 24; 138(7): 2158-2161. doi:10.1021/jacs.5b13458.

\title{
Nanoscale Metal-Organic Frameworks for Ratiometric Oxygen Sensing in Live Cells
}

\author{
Ruoyu Xut ${ }^{\dagger} \S$, Youfu Wang ${ }^{\dagger, \ddagger, \S}$, Xiaopin Duan $^{\dagger}$, Kuangda $\mathrm{Lu}^{\dagger}$, Daniel Micheroni ${ }^{\dagger}$, Aiguo $\mathrm{Hu}^{\ddagger}$, \\ and Wenbin $\operatorname{Lin}^{\dagger}$ \\ Wenbin Lin: wenbinlin@uchicago.edu \\ tDepartment of Chemistry, University of Chicago, 929 East 57th Street, Chicago, Illinois 60637, \\ United States \\ FShanghai Key Laboratory of Advanced Polymeric Materials, School of Materials Science and \\ Engineering, East China University of Science and Technology, Shanghai 200237, China
}

\section{Abstract}

We report the design of a phosphorescence/fluorescence dual-emissive nanoscale metal-organic framework (NMOF), $\mathrm{R}-\mathrm{UiO}$, as an intracellular oxygen $\left(\mathrm{O}_{2}\right)$ sensor. $\mathrm{R}-\mathrm{UiO}$ contains a $\mathrm{Pt}(\mathrm{II})$ porphyrin ligand as an $\mathrm{O}_{2}$-sensitive probe and a Rhodamine-B isothiocyanate ligand as an $\mathrm{O}_{2-}$ insensitive reference probe. It exhibits good crystallinity, high stability, and excellent ratiometric luminescence response to $\mathrm{O}_{2}$ partial pressure. In vitro experiments confirmed the applicability of $\mathrm{R}-\mathrm{UiO}$ as an intracellular $\mathrm{O}_{2}$ biosensor. This work is the first report of a NMOF-based intracellular oxygen sensor and should inspire the design of ratiometric NMOF sensors for other important analytes in biological systems.

Oxygen $\left(\mathrm{O}_{2}\right)$ is a vital component in aerobic respiration that provides metabolic energy to cells. Hypoxia-a reduction in normal levels of $\mathrm{O}_{2}$-is related to various diseases, ${ }^{1}$ including vascular disease, pulmonary disease, and cancer. ${ }^{2}$ For instance, sustained hypoxia in a growing tumor can result in a more aggressive phenotype. ${ }^{3}$ Monitoring and quantifying $\mathrm{O}_{2}$ levels in living cells are thus of great importance for cancer diagnosis, tumor pathophysiology assessment, and evaluation of the therapeutic effects of anticancer treatments. $\mathrm{O}_{2}$ tension can be detected and measured by several methods, including polarographic $\mathrm{O}_{2}$ needle electrodes, ${ }^{4}$ immunohistochemical staining, ${ }^{5}$ positron emission tomography imaging, ${ }^{6}$ magnetic resonance imaging, ${ }^{7}$ and photoluminescence imaging. ${ }^{8}$ Because of their high sensitivity and outstanding spatial resolution, photoluminescencebased techniques provide particularly powerful tools for sensing $\mathrm{O}_{2}$ in living cells.

Correspondence to: Wenbin Lin, wenbinlin@uchicago.edu.

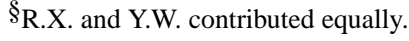

ASSOCIATED CONTENT

Supporting Information

The Supporting Information is available free of charge on the ACS Publications website at DOI: 10.1021/jacs.5b13458.

Experimental details for the synthesis and characterization of $\mathrm{M}-\mathrm{UiO}$ and $\mathrm{R}-\mathrm{UiO} \mathrm{NMOFs}$, oxygen calibration and fitting, cellular uptake, and live cell imaging, including Figures S1-S20 (PDF)

The authors declare no competing financial interest. 
Ratiometric sensing, which uses an $\mathrm{O}_{2}$-insensitive reference and an $\mathrm{O}_{2}$-sensitive probe to measure emission ratios at two different wavelengths, can compensate for signal changes caused by disturbances from the external environment, such as light scattering and fluctuations in the excitation source, ${ }^{9}$ allowing for accurate measurements of $\mathrm{O}_{2}$ concentrations. Since Kopelman and co-workers first developed PEEBLEs (probes encapsulated by biologically localized embedding) containing a cyanine dye standard and a Pt-porphyrin phosphor for ratiometric $\mathrm{O}_{2}$ sensing, ${ }^{10}$ a number of polymeric nanoparticles, ${ }^{8 c, e}$ silica gels, ${ }^{11}$ and quantum dots ${ }^{12}$ have emerged as promising ratiometric $\mathrm{O}_{2}$ sensors.

Metal-organic frameworks (MOFs) are an emerging class of porous materials built from metal ions or clusters bridged by organic linkers that have been explored as chemical sensors. ${ }^{13}$ Nanoscale MOFs (NMOFs) have also been used for small molecule sensing ${ }^{14}$ and biomedical imaging. ${ }^{15} \mathrm{NMOFs}$ exhibit several characteristics that make them ideal nanomaterials for biological and biomedical applications. First, NMOFs have good crystallinity and structural tunability, which allow synthetic elaborations for specific applications. Second, NMOFs are highly porous, which allows them to accommodate high loadings of imaging/therapeutic agents, quickly diffuse small molecules (i.e., drugs, analytes), and prevent dye self-quenching. Third, NMOFs do not suffer from agent leaching due to covalent bonding. Fourth, NMOFs are intrinsically biodegradable in the long term due to their relatively labile metal-ligand bonds. ${ }^{16}$ For example, we have recently used a fluorescent NMOF for real-time intracellular $\mathrm{pH}$ sensing ${ }^{15 \mathrm{a}}$ and a porphyrin-based NMOF in photodynamic therapy. ${ }^{17}$ Herein, we report the first NMOF probe for ratiometric $\mathrm{O}_{2}$ sensing in live cells.

We hypothesized that an NMOF with both $\mathrm{O}_{2}$-independent and -sensitive ligands would serve as an excellent ratiometric $\mathrm{O}_{2}$ sensor by taking advantage of the aforementioned features of NMOFs. Pt-5,15-di( $p$-benzoato)porphyrin (DBP-Pt) was chosen as an $\mathrm{O}_{2}$ sensitive bridging ligand, whereas Rhodamine-B isothiocyanate (RITC)-conjugated quaterphenyldicarboxylate (QPDC) was used as an $\mathrm{O}_{2}$-independent ligand to construct a ratiometric NMOF, R-UiO (Scheme 1). Pt-porphyrin shows bright phosphorescence with a long-lived triplet state at ambient temperature, and its phosphorescence intensity is highly dependent on $\mathrm{O}_{2}$ concentration, making it an ideal choice as an $\mathrm{O}_{2}$-sensitive probe in ratiometric $\mathrm{O}_{2}$ sensing. ${ }^{8 \mathrm{c}-\mathrm{e}, 10}$ We selected Rhodamine-B as a reference dye for the following reasons: (1) Absorption of Rhodamine-B and $\mathrm{H}_{2} \mathrm{DBP}-\mathrm{Pt}$ at $500-540 \mathrm{~nm}$ allows for the simultaneous excitation of both dyes (Figure S5). (2) The non-overlap of Rhodamine-B fluorescence $(570 \mathrm{~nm})$ and $\mathrm{H}_{2} \mathrm{DBP}-\mathrm{Pt}$ phosphorescence $(630 \mathrm{~nm})$ (Figure S5) facilitates ratiometric luminescence quantifications. (3) The $\mathrm{pH}$-independent fluorescence of Rhodamine- $\mathrm{B}$ at $\mathrm{pH}>6$ prevents disturbance due to cellular $\mathrm{pH}$ changes. ${ }^{18}$ (4) Emissions of both dyes at relatively long wavelengths $(>570 \mathrm{~nm}$ ) minimize background autofluorescence from live cells.

We further hypothesized that a mixed-ligand NMOF with both DBP-Pt and aminoquaterphenyldicarboxylate (QPDC-NH 2 ) could be built due to the similar lengths of these ligands. We observed that the unit cell parameter of Zn-DPDBP-UiO ${ }^{17}$ (38.76 ̊, DPDBP = 10,20-diphenyl-5,15-di(p-benzoato)-porphyrin), whose ligand is similar in structure to DBP- 
$\mathrm{Pt}$, is only $0.2 \%$ larger than that of TPHN-UiO ${ }^{19}\left(38.68 \AA\right.$, TPHN $=4,4^{\prime}$ -

bis(carboxyphenyl)-2-nitro-1,1' -biphenyl). The QPDC- $\mathrm{NH}_{2}$ ligands in the mixed-ligand NMOF could be readily conjugated with RITC to afford the dual-emissive R-UiO NMOF.

Furthermore, the relative intensities of RITC fluorescence and DBP-Pt phosphorescence can be tuned by adjusting the feed ratio of the two dyes during MOF synthesis and postsynthesis modification, respectively.

$\mathrm{H}_{2}$ QPDC- $\mathrm{NH}_{2}$ was obtained by Suzuki coupling between $4,4^{\prime}$-dibromo-2-amino-1, $1^{\prime}$ biphenyl and 4-methoxycarbonylphenylboronic acid, followed by hydrolysis. $\mathrm{H}_{2}$ DBP-Pt was synthesized by metalation of 5,15-di(4-methoxycarbonyl)-porphyrin ( $\left.\mathrm{Me}_{2} \mathrm{DBP}\right)$ with $\mathrm{K}_{2} \mathrm{PtCl}_{4}$ in benzonitrile under reflux, followed by hydrolysis in basic conditions, and characterized by NMR spectroscopy and mass spectrometry (Scheme S2). A solvothermal reaction between $\mathrm{H}_{2} \mathrm{DBP}-\mathrm{Pt}, \mathrm{H}_{2} \mathrm{QPDC}-\mathrm{NH}_{2}$, and $\mathrm{HfCl}_{4}$ in $\mathrm{N}, \mathrm{N}$-dimethylformamide (DMF) at $80{ }^{\circ} \mathrm{C}$ afforded the mixed-ligand NMOF, M-UiO, as an orange powder (Scheme 1). Transmission electron microscopy (TEM) revealed hexagonal plate morphology with a diameter of $\sim 200 \mathrm{~nm}$ and a thickness of $\sim 30 \mathrm{~nm}$ (Figure 1b). Powder X-ray diffraction (PXRD), high-resolution TEM, and fast Fourier transform patterns showed that M-UiO displayed good crystallinity (Figures 1). The distance between adjacent secondary building units was measured to be $\sim 2.26 \mathrm{~nm}$ by TEM, consistent with the distance of $2.18 \mathrm{~nm}$ calculated from the PXRD data. UV-vis spectrum of M-UiO showed only two Q-band peaks, suggesting no Pt leaching during NMOF synthesis (Figure S4). ${ }^{19}$ Inductively coupled plasma-mass spectrometry (ICP-MS) gave a DBP-Pt:QPDC-NH $\mathrm{N}_{2}$ molar ratio of 6.2:93.8 in M-UiO.

Rhodamine-B was covalently attached to $\mathrm{M}-\mathrm{UiO}$ by forming the thiourea linkage between QPDC-NH $\mathrm{N}_{2}$ and RITC in R-UiO, which was confirmed by mass spectrometry (Figure S6). TEM images and PXRD patterns showed that R-UiO retained the plate-like morphology and the crystallinity of M-UiO (Figure 1a,f). Dynamic light scattering measurements gave an average diameter of $177.8(\mathrm{PDI}=0.064)$ and $181.1(\mathrm{PDI}=0.079)$ for $\mathrm{M}-\mathrm{UiO}$ and $\mathrm{R}-\mathrm{UiO}$, respectively. The loadings of Rhodamine-B could be adjusted by controlling the feed amount of RITC, leading to R-UiO-1 and R-UiO-2 that contain 0.6 and 1.6 mol\% Rhodamine-B, respectively (Figures S12 and S13).

R-UiO was incubated in Hank's Balanced Salt Solution (HBSS) buffer for $24 \mathrm{~h}$ to evaluate its stability in physiological conditions. After incubation, the $\mathrm{d}_{111}$ peak in the PXRD pattern was split into two peaks (Figure 1a), likely due to minor lattice distortion in the buffer solution. Nevertheless, TEM image clearly indicated the preservation of lattice fringes (Figures 2f, S9, and S10). Moreover, there is no Rhodamine-B or DBP-Pt leaching after incubation (Figure S8), suggesting adequate stability for oxygen sensing in the media.

To achieve ratiometric quantification using a single excitation and simultaneous detection of RITC fluorescence and DBP-Pt phosphorescence, there cannot be energy transfer from DBP-Pt to Rhodamine-B. This lack of energy transfer was confirmed by (1) a negligible overlap between $\mathrm{H}_{2}$ DBP-Pt emission and Rhodamine-B absorption (Figure S5), (2) the presence of only characteristic DBP-Pt phosphorescence, but not RITC fluorescence upon exciting R-UiO at $391 \mathrm{~nm}$ (corresponding to $\mathrm{H}_{2} \mathrm{DBP}-\mathrm{Pt}$ soret band, Figure S11), and (3) 
similar phosphorescence lifetimes of $\mathrm{R}-\mathrm{UiO}$ and $\mathrm{H}_{2} \mathrm{DBP}-\mathrm{Pt}$ (Figure S16). Ratiometric sensing was first carried out by fluorimetry with a $514 \mathrm{~nm}$ excitation light source in order to match the laser in confocal laser scanning microscopy (CLSM). Under a nitrogen-saturated atmosphere ( $p_{\mathrm{O}_{2}}=0 \mathrm{mmHg}$ ), R-UiO-1 showed a strong emission at $630 \mathrm{~nm}$ from DBP-Pt and a weak emission at $570 \mathrm{~nm}$ attributed to RITC (Figure 2a). As $p_{\mathrm{O}_{2}}$ gradually increased to aerated atmosphere $\left(p_{\mathrm{O}_{2}}=160 \mathrm{mmHg}\right)$, the RITC fluorescence remained unchanged, while the DBP-Pt phosphorescence decreased significantly as expected. We quantitatively analyzed oxygen quenching by fitting the data to the Stern-Volmer equation, ${ }^{20}$

$$
\frac{R_{\mathrm{I}}^{0}}{R_{\mathrm{I}}}=1+K_{\mathrm{SV}} p_{\mathrm{O}_{2}}
$$

where $K_{\mathrm{SV}}$ is the Stern-Volmer constant, and $R_{\mathrm{I}}^{0}=I_{\mathrm{P}}^{0} / I_{\mathrm{F}}^{0}$ and $R_{\mathrm{I}}=I_{\mathrm{P}} / I_{\mathrm{F}}$ are the ratios of phosphorescence intensity to fluorescence intensity in the absence and presence of oxygen, respectively. $R_{\mathrm{I}}^{0} / R_{\mathrm{I}}$ showed a good linear relationship with respect to $p_{\mathrm{O}_{2}}$ up to $80 \mathrm{mmHg}$ (Figure 2b). Beyond this point, the ratio deviated from the Stern-Volmer plot (Figure S14). Such a deviation was also observed in previous reports ${ }^{7,21}$ and is probably related to the complicated dynamics involved in the MOF structure. Fortunately, $p_{\mathrm{O}_{2}}$ in biological tissues is typically below $70 \mathrm{mmHg}$ (except in arterial blood). ${ }^{22}$ Within this range, the intensity ratio fitted well to the Stern-Volmer equation with $K_{\mathrm{SV}}=0.015 \mathrm{mmHg}^{-1}$. The $\mathrm{O}_{2}$ quenching experiment proved that $\mathrm{R}-\mathrm{UiO}$ is a good $\mathrm{O}_{2}$ sensor by providing $p_{\mathrm{O}_{2}}$-specific $I_{\mathrm{P}} / I_{\mathrm{F}}$ ratios.

To further confirm the validity of ratiometric measurements using R-UiO, the phosphorescence lifetime of R-UiO-1 in HBSS buffer was measured under different $p_{\mathrm{O}_{2}}$ (Figure 2c). The data were fitted by bi-exponential decay. The amplitude weighted lifetime $\tau$ $(28.1 \mu \mathrm{s})$ in a deoxygenated $(0 \mathrm{mmHg})$ atmosphere steadily decreased as $p_{\mathrm{O}_{2}}$ increased and reached $7.54 \mu \mathrm{s}$ in an aerated atmosphere $(160 \mathrm{mmHg})$. The lifetime was fitted according to eq 2 (Figure 2d):

$$
\frac{\tau^{0}}{\tau}=1+K_{\mathrm{SV}} p_{O_{2}}
$$

where $\tau^{0}$ and $\tau$ are weighted lifetimes in the absence and presence of oxygen, respectively. The obtained $K_{\mathrm{SV}}=0.017 \mathrm{mmHg}^{-1}$ is similar to the ratiometric measurement result, which indicates negligible static quenching of R-UiO-1.

Next we tested the validity of the ratiometric sensors by CLSM. R-UiO-2 was dispersed in HBSS buffer and subjected to CLSM imaging under different $p_{\mathrm{O}_{2}}$. Upon excitation with a $514 \mathrm{~nm}$ agon laser, signals in the ranges of 620-660 and 540-580 nm were collected in two separate channels (Figure S17) and analyzed by ImageJ to quantify the intensity ratios, $I_{\mathrm{P}} / I_{\mathrm{F}}$. Notably, the $I_{\mathrm{P}} / I_{\mathrm{F}}-p_{\mathrm{O}_{2}}$ curve deviates from that obtained by fluorimetry (Figure 2a), which is reasonable, given that the process of collecting photoluminescence on a CLSM is much more complicated than using a fluorimeter. Many factors besides $p_{\mathrm{O}_{2}}$ such as laser power and dwell time can influence the absolute and relative intensities of phosphorescence/ 
fluorescence. ${ }^{23} \mathrm{We}$ also noticed that the phosphorescence component was more prominent under CLSM with our instrument settings, so we used R-UiO-2 with a higher RITC loading for CLSM experiments. The $I_{\mathrm{P}} / I_{\mathrm{F}}-p_{\mathrm{O}_{2}}$ curves obtained by CLSM are highly reproducible with the $I_{\mathrm{P}} / I_{\mathrm{F}}$ ratio gradually decreasing as $p_{\mathrm{O}_{2}}$ increases, and are fitted with a rational function (fomula $\mathrm{S} 2, \mathrm{SI}$ ) which serves as a standard curve for intracellular $p_{\mathrm{O}_{2}}$ measurements.

We chose mouse colon carcinoma CT26 cells with a low background autofluorescence for in vitro imaging. The cellular uptake of R-UiO-2 in CT26 cells was first investigated by incubating CT26 cells with $30 \mu \mathrm{g} / \mathrm{mL}$ R-UiO-2 for different times. Cytotoxicity assay indicates that R-UiO is biocompatible (Figure S18). Time-dependent endocytosis was quantified by ICP-MS and shown in Figure $3 \mathrm{~b}$. Efficient cellular uptake $(\sim 2.5 \mathrm{pg} / \mathrm{cell})$ was observed after a $2 \mathrm{~h}$ incubation, which indicates feasibility for intracellular $p_{\mathrm{O}_{2}}$ measurements.

Finally, we used R-UiO-2 to examine cellular $\mathrm{O}_{2}$ levels. CT26 cells were incubated with RUiO-2 for $2 \mathrm{~h}$. The culturing media were then exchanged to HBSS buffer with different $p_{\mathrm{O}_{2}}$ in a sealed chamber, and cells were incubated for another $15 \mathrm{~min}$ to ensure efficient oxygen exchange across cell plasma membranes. CLSM settings were identical to those used for the calibration curve. We tested three different $p_{\mathrm{O}_{2}}$ conditions: 4,32 , and $160 \mathrm{mmHg}$, which represent hypoxia, normoxia and aerated conditions, respectively. Different channels of cellular uptake of R-UiO-2 captured by CLSM are shown in Figure S19. The $I_{\mathrm{P}} / I_{\mathrm{F}}$ ratios of R-UiO-2 are shown by pseudocolor images in Figure $3 \mathrm{c}$. The $I_{\mathrm{P}} / I_{\mathrm{F}}$ values of internalized RUiO-2 analyzed by ImageJ were $5.29 \pm 0.12,4.45 \pm 0.09$, and $2.80 \pm 0.06$, corresponding to $5.1 \pm 2.5,27.3 \pm 3.1$, and $158 \pm 11 \mathrm{mmHg}$ (see SI for error analysis), respectively, according to the calibration curve in Figure 3a. The results matched well with the preset $p_{\mathrm{O}_{2}}$ in each chamber. These data suggest the broad range and good accuracy of R-UiO as intracellular oxygen sensor.

In conclusion, we have for the first time reported the rational design and synthesis of stable, crystalline, porous, and dual-emissive R-UiO NMOFs for ratiometric sensing of intracellular oxygen in live cells. This study should inspire the design of NMOF sensors for other biologically important analytes by taking advantage of the synthetic tunability, structural versatility, and other unique attributes of NMOFs.

\section{Supplementary Material}

Refer to Web version on PubMed Central for supplementary material.

\section{Acknowledgments}

We thank the NIH (UO1-CA198989 and P30 CA014599) for funding support and Dr. Vytas Bindokas for help with confocal microscopy imaging. Additional support was provided by the Chicago MRSEC, which is funded by NSF through grant DMR-1420709.

\section{REFERENCES}

1. Ikeda. Pathol. Int. 2005; 55:603-610. [PubMed: 16185289] 
2. Harris AL. Nat. Rev. Cancer. 2002; 2:38-47. [PubMed: 11902584]

3. Höckel M, Schlenger K, Aral B, Mitze M, Schäffer U, Vaupel P. Cancer Res. 1996; 56:4509-4515. [PubMed: 8813149]

4. Gatenby RA, Kessler HB, Rosenblum JS, Coia LR, Moldofsky PJ, Hartz WH, Broder G. Int. J. Radiat. Oncol. Biol. Phys. 1988; 14:831-838. [PubMed: 3360652]

5. Hoogsteen IJ, Lok J, Marres HA, Takes RP, Rijken PF, van der Kogel AJ, Kaanders JH. Eur. J. Cancer. 2009; 45:2906-2914. [PubMed: 19699082]

6. Mees G, Dierckx R, Vangestel C, Van de Wiele C. Eur. J. Nucl. Med. Mol. Imaging. 2009; 36:16741686. [PubMed: 19565239]

7. (a) Cooper RA, Carrington BM, Loncaster JA, Todd SM, Davidson SE, Logue JP, Luthra AD, Jones AP, Stratford I, Hunter RD. Radiother. Oncol. 2000; 57:53-59. [PubMed: 11033189] (b) Padhani AR, Krohn KA, Lewis JS, Alber M. Eur. Radiol. 2007; 17:861-872. [PubMed: 17043737]

8. (a) Zhang G, Palmer GM, Dewhirst MW, Fraser CL. Nat. Mater. 2009; 8:747-751. [PubMed: 19668206] (b) Spencer JA, Ferraro F, Roussakis E, Klein A, Wu J, Runnels JM, Zaher W, Mortensen LJ, Alt C, Turcotte R, et al. Nature. 2014; 508:269-273. [PubMed: 24590072] (c) Wu C, Bull B, Christensen K, McNeill J. Angew. Chem. Int. Ed. 2009; 48:2741-2745.(d) Wang, X-d; Stolwijk, JA.; Lang, T.; Sperber, M.; Meier, RJ.; Wegener, J.; Wolfbeis, OS. J. Am. Chem. Soc. 2012; 134:17011-17014. [PubMed: 23017056] (e) Zhao Q, Zhou X, Cao T, Zhang KY, Yang L, Liu S, Liang H, Yang H, Li F, Huang W. Chem. Sci. 2015; 6:1825-1831.(f) Yoshihara T, Yamaguchi Y, Hosaka M, Takeuchi T, Tobita S. Angew. Chem. Int. Ed. 2012; 51:4148-4151.

9. Feng Y, Cheng J, Zhou L, Zhou X, Xiang H. Analyst. 2012; 137:4885-4901. [PubMed: 22943050]

10. Koo Y-EL, Cao Y, Kopelman R, Koo SM, Brasuel M, Philbert MA. Anal. Chem. 2004; 76:24982505. [PubMed: 15117189]

11. Chojnacki P, Mistlberger G, Klimant I. Angew. Chem. Int. Ed. 2007; 46:8850-8853.

12. Amelia M, Lavie-Cambot A, McClenaghan ND, Credi A. Chem. Commun. 2011; 47:325-327.

13. (a) Kreno LE, Leong K, Farha OK, Allendorf M, Van Duyne RP, Hupp JT. Chem. Rev. 2012; 112:1105-1125. [PubMed: 22070233] (b) Liu D, Lu K, Poon C, Lin W. Inorg. Chem. 2014; 53:1916-1924. [PubMed: 24251853] (c) Hu Z, Deibert BJ, Li J. Chem. Soc. Rev. 2014; 43:58155840. [PubMed: 24577142] (d) Guo Z, Song X, Lei H, Wang H, Su S, Xu H, Qian G, Zhang H, Chen B. Chem. Commun. 2015; 51:376-379.

14. (a) Yang W, Feng J, Song S, Zhang H. ChemPhysChem. 2012; 13:2734-2738. [PubMed: 22706989] (b) Suresh VM, Chatterjee S, Modak R, Tiwari V, Patel AB, Kundu TK, Maji TK. J. Phys. Chem. C. 2014; 118:12241-12249.(c) Wu P, Wang J, He C, Zhang X, Wang Y, Liu T, Duan C. Adv. Funct. Mater. 2012; 22:1698-1703.

15. (a) He C, Lu K, Lin W. J. Am. Chem. Soc. 2014; 136:12253-12256. [PubMed: 25136764] (b) Taylor KM, Rieter WJ, Lin W. J. Am. Chem. Soc. 2008; 130:14358-14359. [PubMed: 18844356] (c) deKrafft KE, Xie Z, Cao G, Tran S, Ma L, Zhou OZ, Lin W. Angew. Chem. Int. Ed. 2009; 48:9901-9904.(d) Hatakeyama W, Sanchez TJ, Rowe MD, Serkova NJ, Liberatore MW, Boyes SG. ACS Appl. Mater. Interfaces. 2011; 3:1502-1510. [PubMed: 21456529] (e) Foucault-Collet A, Gogick KA, White KA, Villette S, Pallier A, Collet G, Kieda C, Li T, Geib SJ, Rosi NL. Proc. Natl. Acad. Sci. U. S. A. 2013; 110:17199-17204. [PubMed: 24108356]

16. McKinlay AC, Morris RE, Horcajada P, Férey G, Gref R, Couvreur P, Serre C. Angew. Chem. Int. Ed. 2010; 49:6260-6266.

17. Lu K, He C, Lin W. J. Am. Chem. Soc. 2014; 136:16712-16715. [PubMed: 25407895]

18. Coppeta J, Rogers C. Exp. Fluids. 1998; 25:1-15.

19. Manna K, Zhang T, Greene FX, Lin W. J. Am. Chem. Soc. 2015; 137:2665-2673. [PubMed: 25640998]

20. (a) Valeur, B.; Berberan-Santos, MN. Molecular fluorescence: principles and applications. New York: John Wiley \& Sons; 2012. (b) Turro, NJ.; Ramamurthy, V.; Scaiano, JC. Modern molecular photochemistry of organic molecules. New York: Wiley Online Library; 2012.

21. Zhang G, Chen J, Payne SJ, Kooi SE, Demas J, Fraser CL. J. Am. Chem. Soc. 2007; 129:89428943. [PubMed: 17608480]

22. Carreau A, Hafny-Rahbi BE, Matejuk A, Grillon C, Kieda C. J. Cell. Mol. Med. 2011; 15:12391253. [PubMed: 21251211] 
23. Finikova OS, Lebedev AY, Aprelev A, Troxler T, Gao F, Garnacho C, Muro S, Hochstrasser RM, Vinogradov SA. ChemPhysChem. 2008; 9:1673-1679. [PubMed: 18663708] 

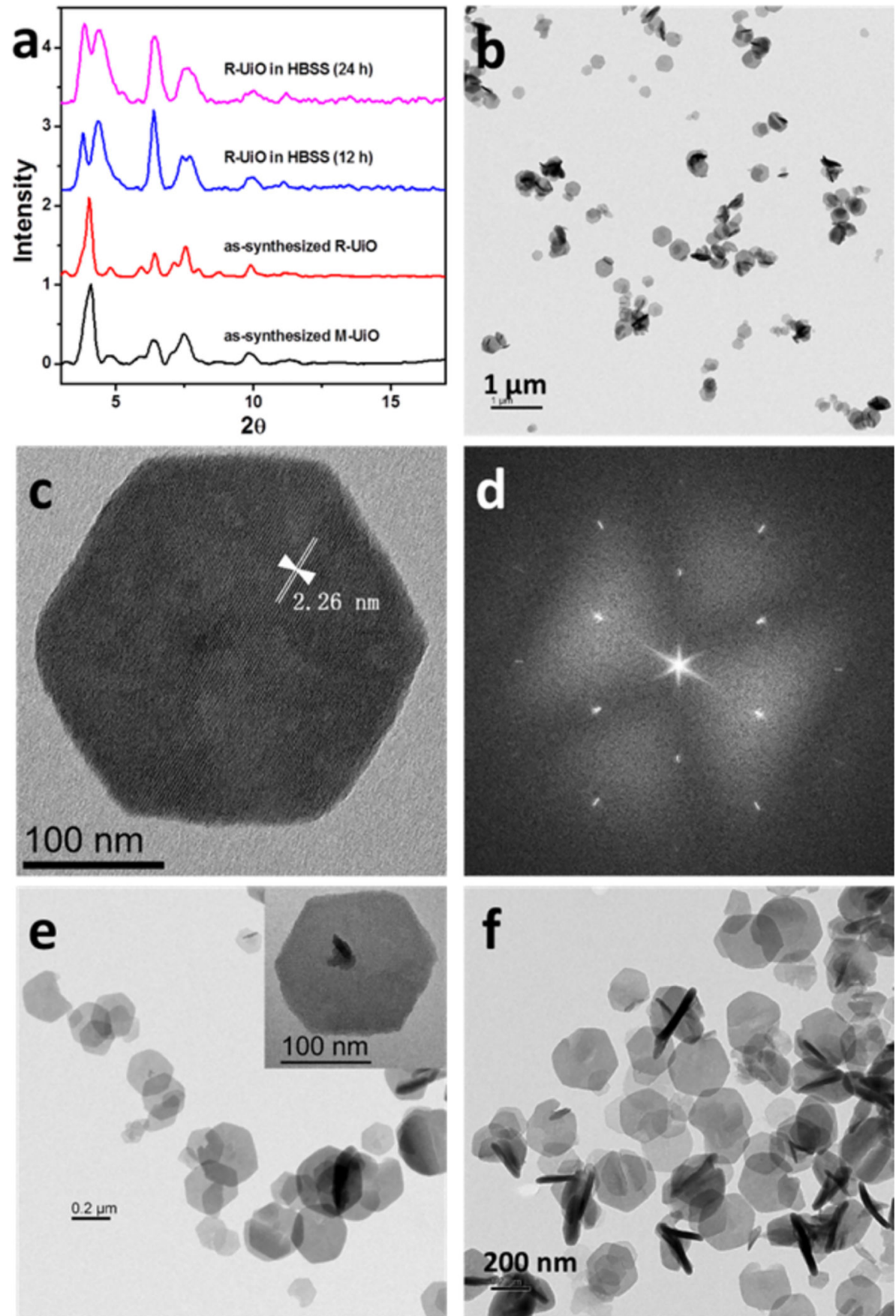

Figure 1.

Structure and morphology of mixed-ligand M-UiO and R-UiO NMOF. (a) PXRD patterns of M-UiO, as-synthesized R-UiO and R-UiO after incubation in HBSS for 12 and $24 \mathrm{~h}$. (b) TEM, (c) high-resolution TEM, and (d) fast Fourier transform patterns of M-UiO. TEM images of R-UiO (e) before and (f) after incubation in HBSS for $24 \mathrm{~h}$. 

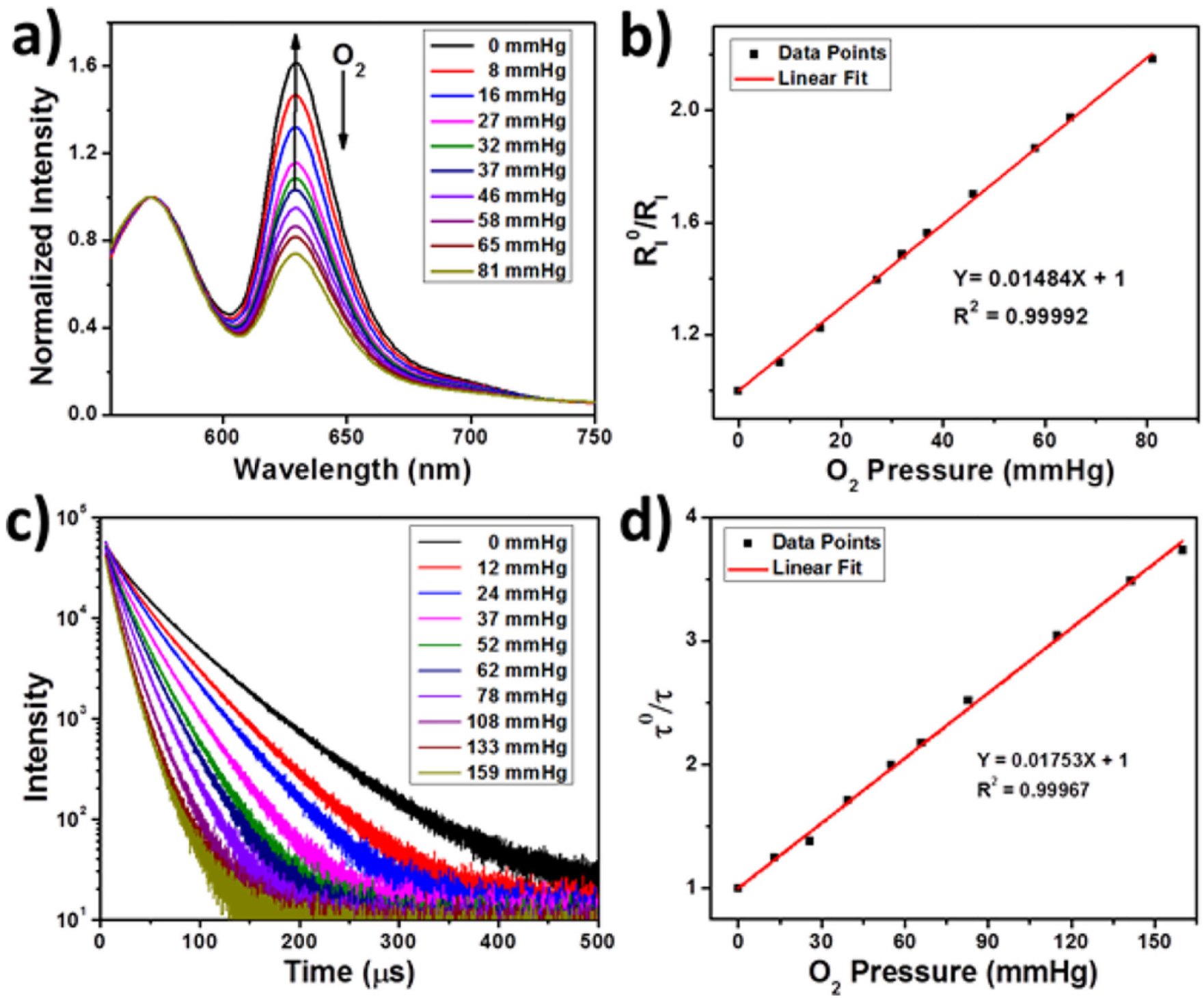

Figure 2.

(a) Emission spectra $\left(\lambda_{\mathrm{ex}}=514 \mathrm{~nm}\right)$ and (c) phosphorescent decays $\left(\lambda_{\mathrm{ex}}=405 \mathrm{~nm}\right)$ of R-

UiO-1 in HBSS buffer under various oxygen partial pressures. Plots of $R_{\mathrm{I}}^{0} / R_{\mathrm{I}}$ (b) and $\tau^{0} / \tau$ (d) as a function of oxygen pressure. 

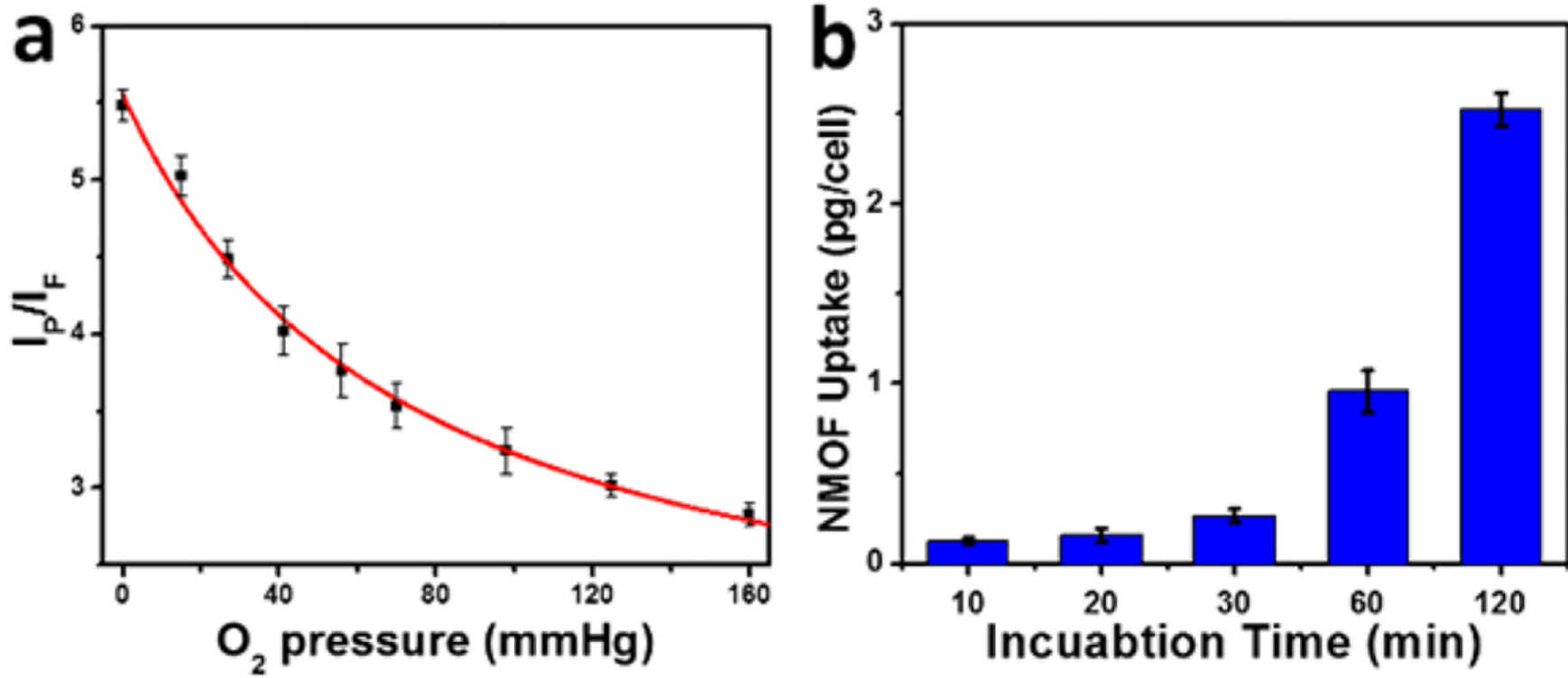

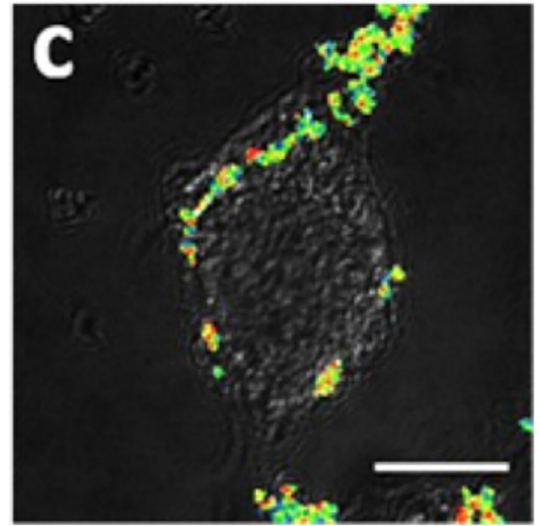

$5.1 \pm 2.5 \mathrm{mmHg}$

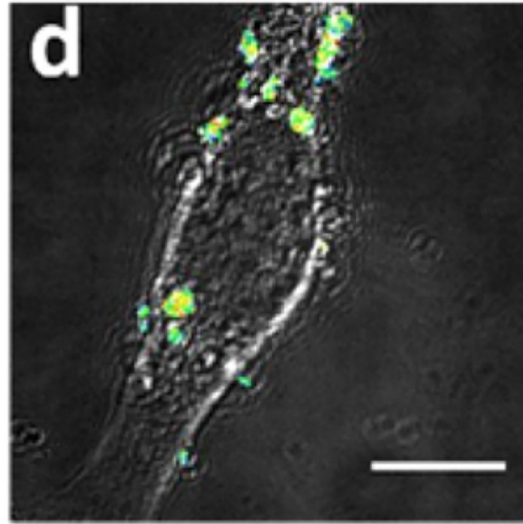

$27.3 \pm 3.1 \mathrm{mmHg}$

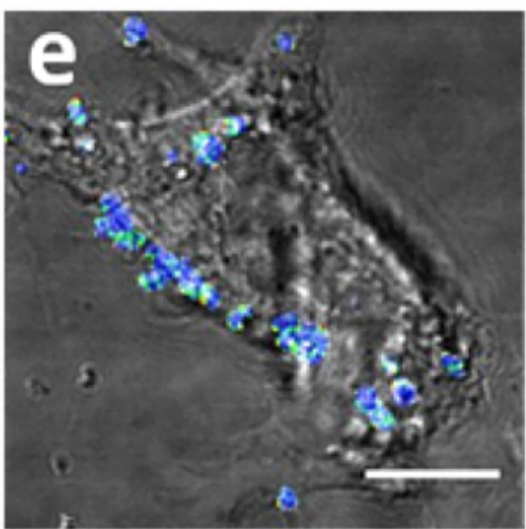

$158 \pm 11 \mathrm{mmHg}$

Figure 3.

(a) Calibration curve of the phosphorescence/fluorescence intensity of R-UiO-2 on CLSM under different oxygen partial pressures. (b) Time-dependent cellular uptake of R-UiO-2 in CT26 cells determined by ICP-MS. Ratiometric luminescence imaging $\left(\lambda_{\mathrm{ex}}=514 \mathrm{~nm}\right)$ of CT26 cells after incubation with R-UiO-2 under (c) hypoxia, (d) normoxia, and (e) aerated conditions. Scale bar: $10 \mu \mathrm{m}$. 
$\mathrm{H}_{2}$ QPDC- $\mathrm{NH}_{2}$
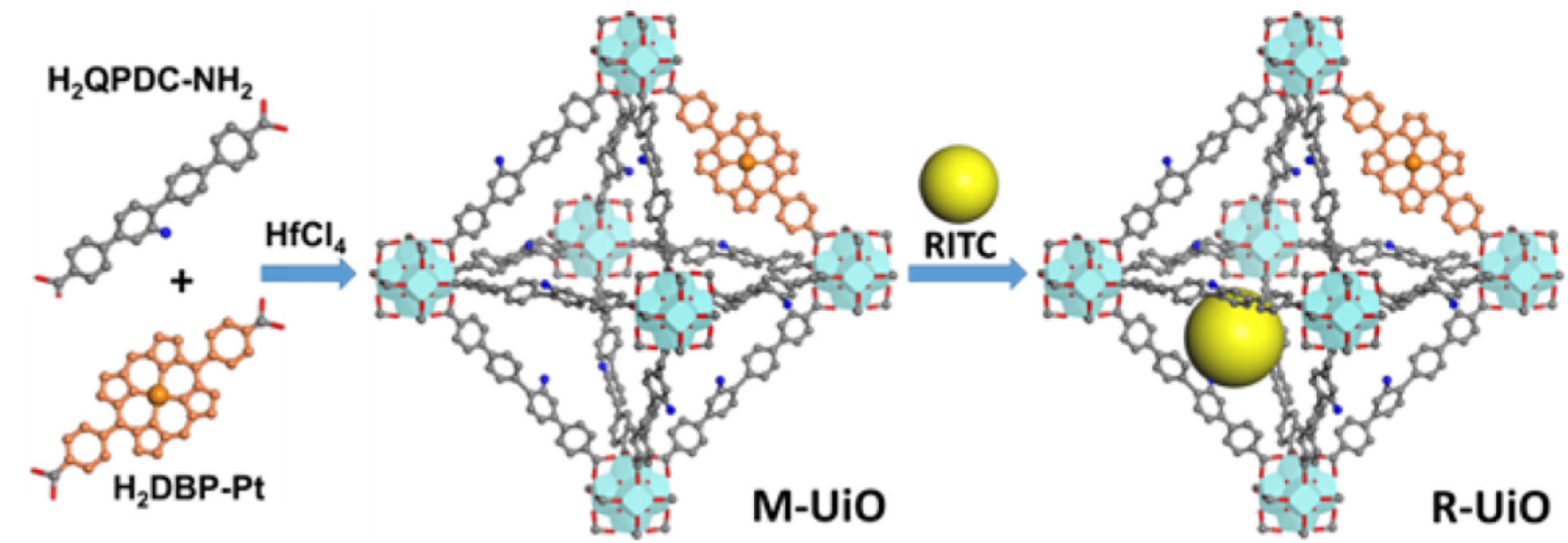

Scheme 1.

Synthesis of Mixed-Ligand M-UiO NMOF and Its Postsynthesis Modification To Afford RUiO NMOF 